\title{
Monte Carlo characterization and benchmarking of extended range REM meters for its application in shielding and radiation area monitoring in Compact Proton Therapy Centers (CPTC)
}

\author{
Gonzalo F. García-Fernández ${ }^{\mathrm{a}, \mathrm{b}, *}$, Lenin E. Cevallos-Robalino ${ }^{\mathrm{a}, \mathrm{c}}$, Roberto García-Baonza ${ }^{\mathrm{a}}$, Eduardo Gallego ${ }^{\mathrm{a}}$, Héctor R. Vega-Carrillo $^{\mathrm{d}}, \mathrm{Karen}^{\mathrm{A} .}$ Guzman-García ${ }^{\mathrm{a}}$, \\ Alfredo Lorente ${ }^{a}$, Sviatoslav Ibáñez ${ }^{a}$
}

\footnotetext{
a Departamento de Ingeniería Energética, ETSI Industriales, Universidad Politécnica de Madrid, José Gutiérrez Abascal 2, 28006, Madrid, Spain

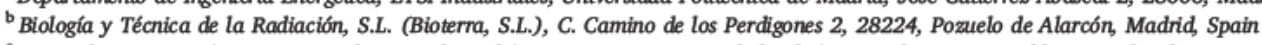

'Gnupo de Imvestigación en Sistemas de Control y Robótica, GISCOR, Universidad Politécnica Salesiana, C. Robles 107 Chambers, 090108, Guayas, Guayaquil, Ecuador

'Unidad Académica de Estudios Nucleares, Universidad Autónoma de Zacatecas, C. Cóprés, 10, 98060, Zacatecas, Zac, Mexico
}

\section{H I G H L I G H T S}

- CPTC involve advanced technologies and smaller footprint and represents the next step in the evolution of proton therapy.

- Response of WENDI-II and LUPIN-II was assessed for its application in verification of shielding against neutrons in CPTC.

- The benchmark in monoenergetic neutron fields was carried out calculating the ambient dose equivalent $\mathrm{H}^{*}(10)$ with MCNP6.

- The performance in continuous neutron fields have been carried out with experimental measurements using an AmBe/241 source.

\section{A B S T R A C T}

Compact Proton Therapy Centers, CPTC, have a single treatment room, and are technologically more affordable, smaller, advanced and easier to use. From a radiological protection point of view, the leading concern in CPTC are interactions of protons with components of the facility and patients that yield a broad emission of secondary particles, mainly highenergy neutrons, up to $230 \mathrm{MeV}$, and photons. Optimal design of shielding involves theoretical assumptions in the design phase and, consequently, experimental measurements with extended range neutron detectors must be carried out in the facility during the commissioning period to verify the design, assumptions and building of the enclosures. There are almost 50 CPTC under construction and planning around the world, hence the improvement of methodologies to verify the shielding and to evaluate the dose to workers and general public in CPTC is a trending issue.

The aim of this work was to evaluate and compare the response of two commercial extended range REM meters, WENDI-II and LUPIN-II, for their application in shielding verification and radiation area monitoring in CPTC facilities, by estimating the ambient dose equivalent, $\mathrm{H}^{*}(10)$, through the Monte Carlo code MCNP6. The results have been compared with previous works. Likewise, the performance evaluation of these devices in continuous energy neutron field have been carried out, using the AmBe/241 neutron source of the Neutronics Hall $(\mathrm{NH})$ of the Neutron Measurements Laboratory of the Energy Engineering Department of Universidad Politecnica de Madrid (LMN-UPM), through Monte Carlo simulation with the MCNP6 code and experimental measurements. The work is framed into the project Contributions to Shielding and Dosimetry of Neutrons in CPTC.

Keywords:

Proton therapy

Compact proton therapy centers

Ambient dose equivalent

WENDI-II

LUPIN-II

MCNP6

\section{Introduction}

Proton therapy (PT), proposed by Robert Wilson in 1946, is an ex ternal radiotherapy that allows control deposition of a great amount of dose at the end of its path, known as Bragg Peak, due to the char acteristic curve of energy deposition for heavy charged particles, namely Bragg Curve, plotted from the mass stopping power law es tablished in 1933 by Bethe and Bloch (Baumann, 2016). Compact

\footnotetext{
* Corresponding author. Doctoral student - UPM, C. José Gutiérrez Abascal, 2, 28006, Madrid, Spain.

E-mail address: gf.garcia@upm.es (G.F. García-Fernández).
} 
Proton Therapy Centers (CPTC) are referred to proton therapy facilities with a single treatment room, maximum two, and representing the actual evolution of proton centers, involving more advanced and af fordable technologies, smaller footprint, and systems easier to use (Degiovanni and Amaldi, 2015). As a consequence of advantages of PT in some clinical cases, nowadays, almost fifty CPTC are under planning and construction around the world (PTCOG, 2018).

The key elements of CPTC are the accelerator room (AR), the proton beam (PB) and the treatment room with a rotating gantry (GTR), and their footprint is approximately $400 \mathrm{~m}^{2}$ (Durante, 2017). Depending on the depth of the treated volume, protons must be accelerated up to $230 \mathrm{MeV}$, yielding many secondary particles in their collisions with structures of the facility and patients, by reactions $(\mathrm{p}, \mathrm{n}),(\mathrm{p}, 2 \mathrm{n}),(\mathrm{p}, \alpha)$ (Mukherjee, 2012). From a radioprotection point of view, the main effects of secondary radiation in CPTC could be summarized as follow (Agosteo, 2001):

1. Dose inside the treatment room, which it involves an unwanted secondary dose in patients (considering protons as primary radia tion).

2. Ambient dose outside the treatment room, which it involves ex posure of staff and the public (calculation and verification of bio logical shielding).

3. Activation in the enclosures walls as well as in the equipment inside the facility.

4. Air activation and neutron skyshine in the air of different rooms of the facility.

5. Activation of water present in the facility (subsoil and circuits of refrigeration).

6. Management of activated materials generated in the operation of facility.

This work is framed inside the project Contributions to Shielding and Dosimetry of Neutrons in CPTC, which involves the development of methodologies to analyze the shielding efficiency and to evaluate the dose to staff and the general public in these facilities, hence, this work is focused on the second point of the aforementioned, but it is also very related to the rest of points.

The main concern about radiological protection in CPTC is stray radiation from high energy neutrons (Paganetti, 2017). The approach for shielding assessment could include estimation of source term, set up of regulatory requirements, design and constructions of walls, and verification of enclosures (Stichelbaut et al., 2014). The dose at the point of interest produced could be estimated using Monte Carlo codes or analytical methods, such us the Point Source line of sight model or Kernel Point, gathered in international codes (NCRP, 2005), and (IAEA, 1998). These complex tasks involve many postulations and hypotheses, and uncertainties usually are within 1.5 and 5 times the calculated value, depending on the assumptions, always on the conservative side, hence shielding must always be verified by using the suitable radiation protection instrumentation, depending on the dosimetry magnitude to be measured (Ipe, 2010).

According to ICRU/ICRP, the operational quantity used in evalua tion of effectiveness of shielding in irradiation facilities would be the ambient dose equivalent at a point in the radiation field, $H^{*}(d)$, usually at $\mathrm{d}=10 \mathrm{~mm}$ of depth, recommended for penetrating radiation of photons and neutrons (ICRP, 1996). In this way, $\mathrm{H}^{*}(10)$ is obtained through the convolution of neutron fluence, $\Phi(\mathrm{E}), \mathrm{cm}^{-2}$, and the ICRU fluence to ambient dose equivalent conversion function, $\mathrm{h}_{\Phi}(\mathrm{E}), \mathrm{Sv} \cdot \mathrm{cm}^{2}$. On the other hand, the response of the detectors, R (Sv), used in ex perimental measurements could be obtained by the convolution of the absolute response function of the detector, $r(E)$, count $\cdot \mathrm{cm}^{2}$, the neutron fluence, $\Phi(\mathrm{E}), \mathrm{cm}^{-2}$, and the calibration factor, C, Sv.count ${ }^{-1}$, which cover different physic events depending on the type of detector (Gallego et al., 2004).

CPTC are the response of the vendors to reduce space requirements and investment costs. The key advantage is that CPTC of each supplier have many similarities, which allows a continuous improvement in the assumptions and hypothesis of calculus in the model of facility, adding new data from different researches (Depuydt, 2018).

The aim of this work was to characterize the response and carry out the benchmarking of two commercial extended range REM meters, WENDI II and LUPIN II, for its application in shielding verifications and radiation area monitoring of CPTC facilities, by estimating the ambient dose equivalent, $\mathrm{H}^{*}(10)$, through the Monte Carlo code MCNP6 and experimental measurements.

\section{Materials and methods}

\subsection{REM meters and extended range neutron dosimeters}

The current instrumentation available to measure the ambient dose equivalent and area monitoring due to neutrons are known as REM meters (where rem is roentgen equivalent man, a former unit in CGS systems, equal to $10 \mathrm{mSv}$ ). These devices are based on designs from the 60's: the spherical detector developed by Bramblet (1960) and the cy lindrical detector, proposed by Andersson and Braun (1963). Both in struments had a proportional counter tube with ${ }^{3} \mathrm{He}$ or $\mathrm{BF}_{3}$ inside a block of neutron moderator, usually polyethylene. Later, these pristine REM meters were modified in the 90's with the insertion of layers of heavy metal in order to undergo spallation reactions with fast neutrons, and extend the range of measurement until $\mathrm{GeV}$, surging devices like LINUS (Birattari et al., 1990).

WENDI II (Wide Energy Neutron Detection Instrument), main fea tures in Table 1, is the second version of an Anderson Braun (A B) device, developed by Los Alamos National Laboratory (Thermo Fisher, 2018).

LUPIN II (Long Interval, Ultra Wide dynamic, PIle up free, Neutron rem counter), features in Table 2, is also the second version of an An derson Braun (A B) type, developed by ELSE Nuclear and Politecnico de Milano (Else Nuclear, 2018).

Depending on the type of accelerator used, synchrocyclotrons or synchrotrons, and the mode of proton therapy applied (conventional, arc therapy, or flash in the future), the neutron radiation field present in CPTC can be virtually continuous or pulsed, thus, both instruments could be covering all the options (Farah et al., 2015). In addition, in spite these devices are both Anderson Braun type REM meters, the counter gas is different, with ${ }^{3} \mathrm{He}$ in WENDI II and $\mathrm{BF}_{3}$ in LUPIN II, therefore, it could be useful to compare the behaviour of both pro portional counters in fields of neutron with extended range energy.

\subsection{Modeling REM meters with MCNP6}

\subsubsection{Model of WENDI II}

The geometry and main elements of WENDI II are described ac cording to data from manufacturer (Thermo Fisher, 2018). The external cylinder of polyethylene (PE) has a diameter of $22.86 \mathrm{~cm}$, a height of $21 \mathrm{~cm}$ and a density of $0.93 \mathrm{~g} / \mathrm{cm}^{3}$, with a borated lid on top. The tungsten shell has an inner radius of $4 \mathrm{~cm}$, a thickness of $1.5 \mathrm{~cm}$ and an

Table 1

WENDI-II technical features (Thermo Fisher, 2018).

\begin{tabular}{ll}
\hline Feature & Data \\
\hline Detector Type/Counter & LND- $252180 /{ }^{3} \mathrm{He}$ \\
$\quad$ Active Volume & $23.95 \mathrm{~cm}^{3}$ \\
Moderator/Metal layer & Polyethylene/Tungsten powder \\
PE Diameter/PE Height/Weight & $22.86 \mathrm{~cm} / 21 \mathrm{~cm} / 13.5 \mathrm{~kg}$ \\
Energy Range/Gamma-Discrimination & $0.025 \mathrm{eV}$ to $5 \mathrm{GeV} / \mathrm{High}$ \\
Measuring-Detection Range & $0.01 \mu \mathrm{Sv} / \mathrm{h}$ to $100 \mathrm{mSv} / \mathrm{h}$ for Cf-252 \\
Neutron Sensitivity & $0.84(\mathrm{counts} / \mathrm{s}) /(\mu \mathrm{Sv} / \mathrm{h})$ for Cf- 252 \\
Gamma Sensitivity & $1-5 \mu \mathrm{Sv} / \mathrm{h}$ to $100 \mathrm{mSv} / \mathrm{h}, 662 \mathrm{keV}$ \\
\hline
\end{tabular}


Table 2

LUPIN-II technical features (Else Nuclear, 2018).

\begin{tabular}{ll}
\hline Feature & Data \\
\hline Detector Type/Counter & Centronic-15EB20/25-SHV/BF3 \\
Active Volume & $73.63 \mathrm{~cm}^{3}$ \\
Moderator/Metal layer & Polyethylene/Lead and Cadmium \\
PE Diameter/PE Height/Weight & $25 \mathrm{~cm} / 29.7 \mathrm{~cm} / 18 \mathrm{~kg}$ \\
Energy Range/Gamma-Discrimination & $0.025 \mathrm{eV}$ to $10 \mathrm{GeV} / \mathrm{Very} \mathrm{High}$ \\
Measuring-Detection Range & $0.01 \mathrm{nSv} / \mathrm{h}$ to $100 \mathrm{mSv} / \mathrm{h}$ for AmBe \\
Neutron Sensitivity & $0.6(\mathrm{counts} / \mathrm{s}) /(\mu \mathrm{Sv} / \mathrm{h})$ for AmBe \\
Gamma Sensitivity & $0.5-50 \mathrm{mSv} / \mathrm{h} \mathrm{for} \mathrm{AmBe}$ \\
\end{tabular}

external height of $11.5 \mathrm{~cm}$, with an effective density of $10.624 \mathrm{~g} / \mathrm{cm}^{3}$, and is surrounded by $4 \mathrm{~cm}$ of PE at the bottom. The auxiliary parts like legs and handle have not been included in the model, since they are not relevant to the measurement.

The proportional counter is a high temperature tube, Type LND 252180 , made in stainless steel of $0.5 \mathrm{~cm}$ thickness, filled of ${ }^{3} \mathrm{He}$ at $2 \mathrm{bar}$ of pressure (1520 torr) and density of $0.250 \mathrm{~kg} / \mathrm{m}^{3}$, in agreement with the gas conditions. The active volume of ${ }^{3} \mathrm{He}$ is a cylinder of $23.95 \mathrm{~cm}^{3}$, with a height of $5.13 \mathrm{~cm}$ and an inner diameter of $2.44 \mathrm{~cm}$. For stainless steel AISI 304, was considered a mass composition of $70.6 \% \mathrm{Fe}, 19 \%$ $\mathrm{Cr}, 9.3 \% \mathrm{Ni}, 1 \% \mathrm{Mn}, 0.05 \mathrm{Si}, 0.04 \% \mathrm{C}$ and $0.02 \% \mathrm{~S}$, and a density of $8 \mathrm{~g} / \mathrm{cm}^{3}$. The counter works at $1,200 \mathrm{~V}$, and the detector is insensitive for photons below $50 \mathrm{keV}(1 \mathrm{mV})$, which is the energy threshold of preamplifier FHT 642. The main channel of reactions in the counter tube is inelastic interaction, ${ }^{3} \mathrm{He}(\mathrm{n}, \mathrm{p})^{3} \mathrm{H}$, between thermal neutrons and ${ }^{3} \mathrm{He}$.
The WENDI II was reproduced in MCNP6 using different cells as shown in Fig. 1. The origin of the Cartesian coordinate system is located at the intersection of the vertical and horizontal axes of the source. The main cells are the counter tube filled with ${ }^{3} \mathrm{He}$ (red), the tungsten powder (grey), the polyethylene moderator (dark blue), the borated rubber patch of the counter tube, on the top of the PE cylinder (light grey), the inner air inside counter (light blue), and the outside air surrounding the device (also in light blue).

\subsubsection{Model of LUPIN II}

The geometry and main elements of LUPIN II are also described according to data from manufacturer (Else Nuclear, 2018). The external cylinder of PE has a diameter of $25 \mathrm{~cm}$, a height of $29.7 \mathrm{~cm}$, with density of $0.93 \mathrm{~g} / \mathrm{cm}^{3}$ (medium). The foil of lead is located around counter, in an inner radius of $10.8 \mathrm{~cm}$, a thickness of $1.5 \mathrm{~mm}$ and a height of $14.1 \mathrm{~cm}$. Cadmium sheets with a thickness of $1.5 \mathrm{~mm}$ are placed on the inside face of the lead, surrounded by PE. Auxiliary parts have not been included in the model.

The proportional counter tube is Type Centronic 15EB20/25 SHV made in aluminium, thickness $1.5 \mathrm{~mm}$, filled with $\mathrm{BF}_{3}$ at $200 \mathrm{mmHg}$ $(26,664 \mathrm{~Pa})$ and surrounded by PE. The counter works at $1,180 \mathrm{~V}$ and the logarithmic amplifier has a wide and is suitable to work in pulsed neutron fields. The active volume of $\mathrm{BF}_{3}$, with $96 \%$ of Boron 10 and $4 \%$ of Boron 11, is a cylinder of $73.63 \mathrm{~cm}^{3}$, with a height of $25 \mathrm{~cm}$ and an inner diameter of $1.8 \mathrm{~cm}$. The main channel is inelastic interaction, ${ }^{10} \mathrm{~B}$ $(n, \alpha)^{7} \mathrm{Li}$, between neutrons and ${ }^{10} \mathrm{~B}$.

The LUPIN II was reproduced using different cells depending on the composition and geometry, as shown in Fig. 2. The main cells of model

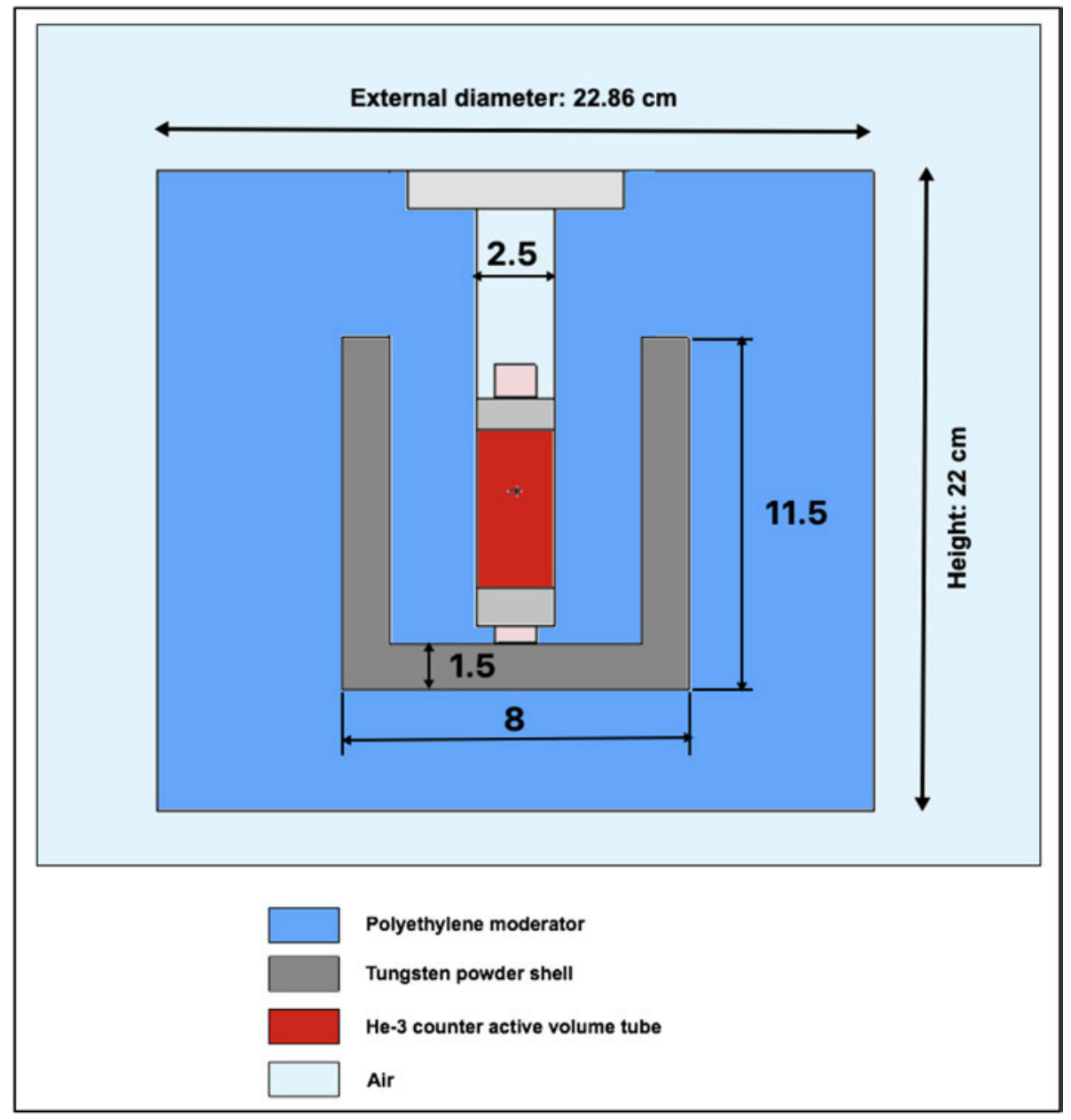

Fig. 1. WENDI-II main dimensions in $\mathrm{cm}$ and cells of MCNP6 model. 


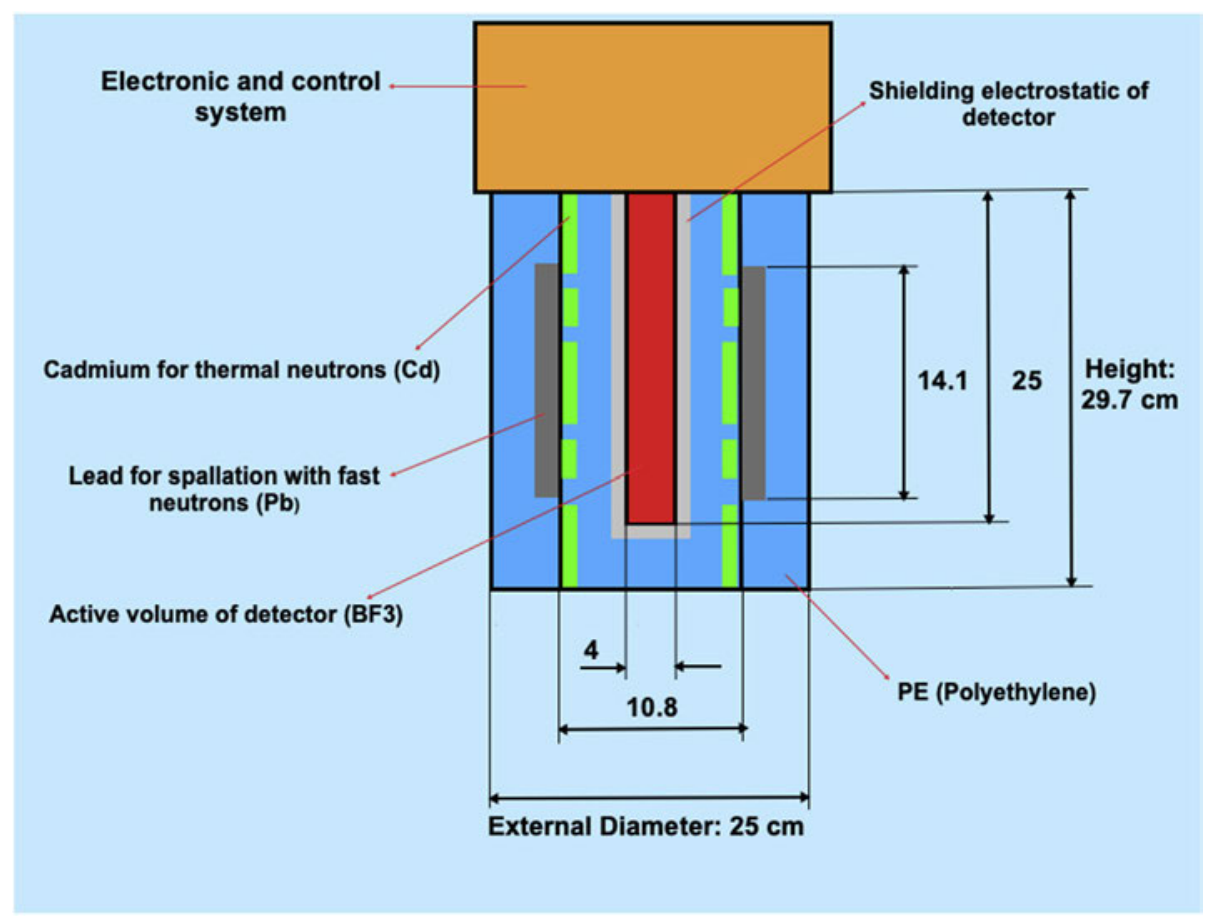

Fig. 2. LUPIN-II dimensions in $\mathrm{cm}$ and main materials in MCNP6 model.

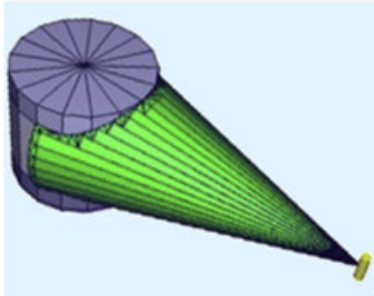

Isotropic Point Source

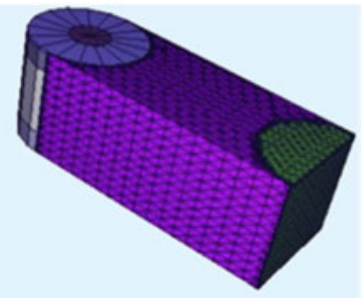

Plane-Parallel Source
Fig. 3. MCNP6 model of irradiation by an isotropic point and a plane-parallel source.

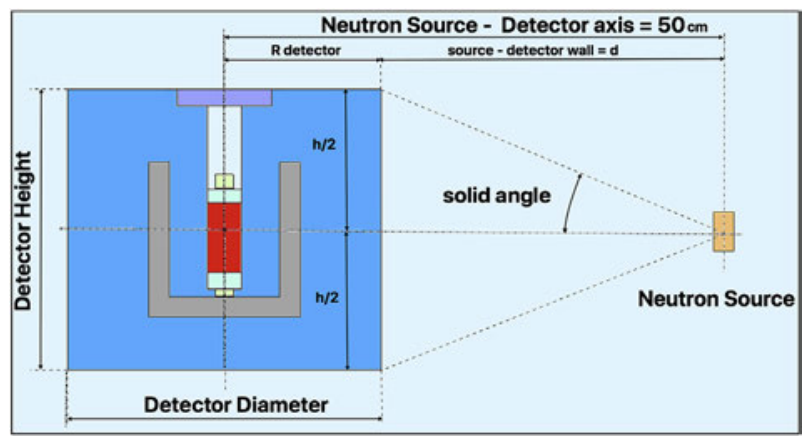

Fig. 4. MCNP6 model of irradiation by an isotropic point source at $50 \mathrm{~cm}$.

are the counter tube filled with $\mathrm{BF}_{3}$ (red), lead foil (grey), cadmium foil (green), polyethylene moderator (dark blue), and the outside air sur rounding the device (light blue). As in WENDI II, the counter cell with $\mathrm{BF}_{3}$, the active volume, will be considered filled of air in several si mulations.

In this work, only the $S(\alpha, \beta)$ thermal treatment for hydrogen was considered for the interactions of neutrons with polyethylene in de tectors. In accordance to the previous works with WENDI II (De Smet et al., 2014), thermal model is more accurate than the default free gas

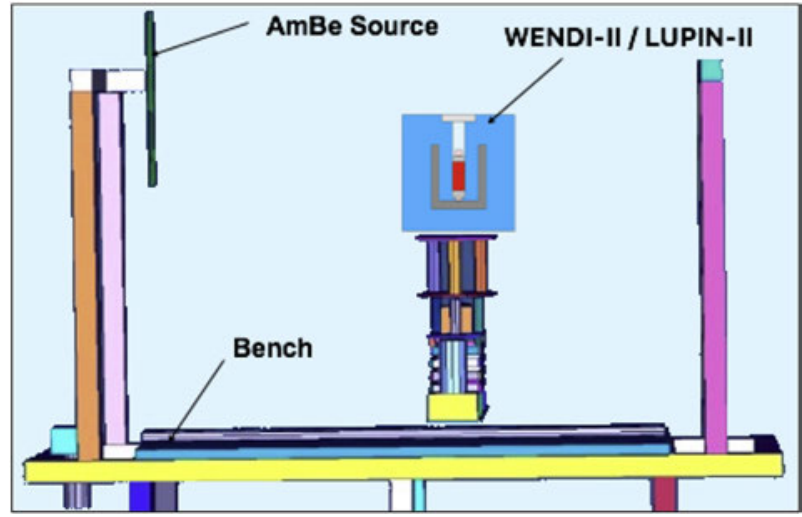

Fig. 5. MCNP6 model of bench inside the Neutronic Hall (NH) at LMN-UPM.

model. In LUPIN II, a preliminary simulation was carried out with both models, verifying that the thermal treatment is also more accurate.

\subsection{Simulation response of REM meters in monoenergetic neutron fields}

\subsubsection{Definition of the neutron source}

Both, lateral irradiation from an isotropic point and from a plane parallel source were considered in preliminary simulations, as shown in Fig. 3, with results very close and finally just irradiation from a point source was considered in the paper, which is commonly assumed in CPTC.

Therefore, the response functions were simulated for lateral irra diation of the REM meters by a monoenergetic neutron source emitting isotropically from a point placed at $50 \mathrm{~cm}$ from the vertical axis of detector, as shown in Fig. 4. The response was simulated for 20 neutron energies between $10^{-9} \mathrm{MeV}$ and $230 \mathrm{MeV}$, with $10^{8}$ stories to achieve an uncertainty lower than $5 \%$. As variance reduction method, the emission was limited to a solid angle circumscribed to the semi height of the detector, with a value of $15.20^{\circ}$ for WENDI II, and $21.60^{\circ}$ for LUPIN II. All the results were obtained by emitted neutron from the source. 


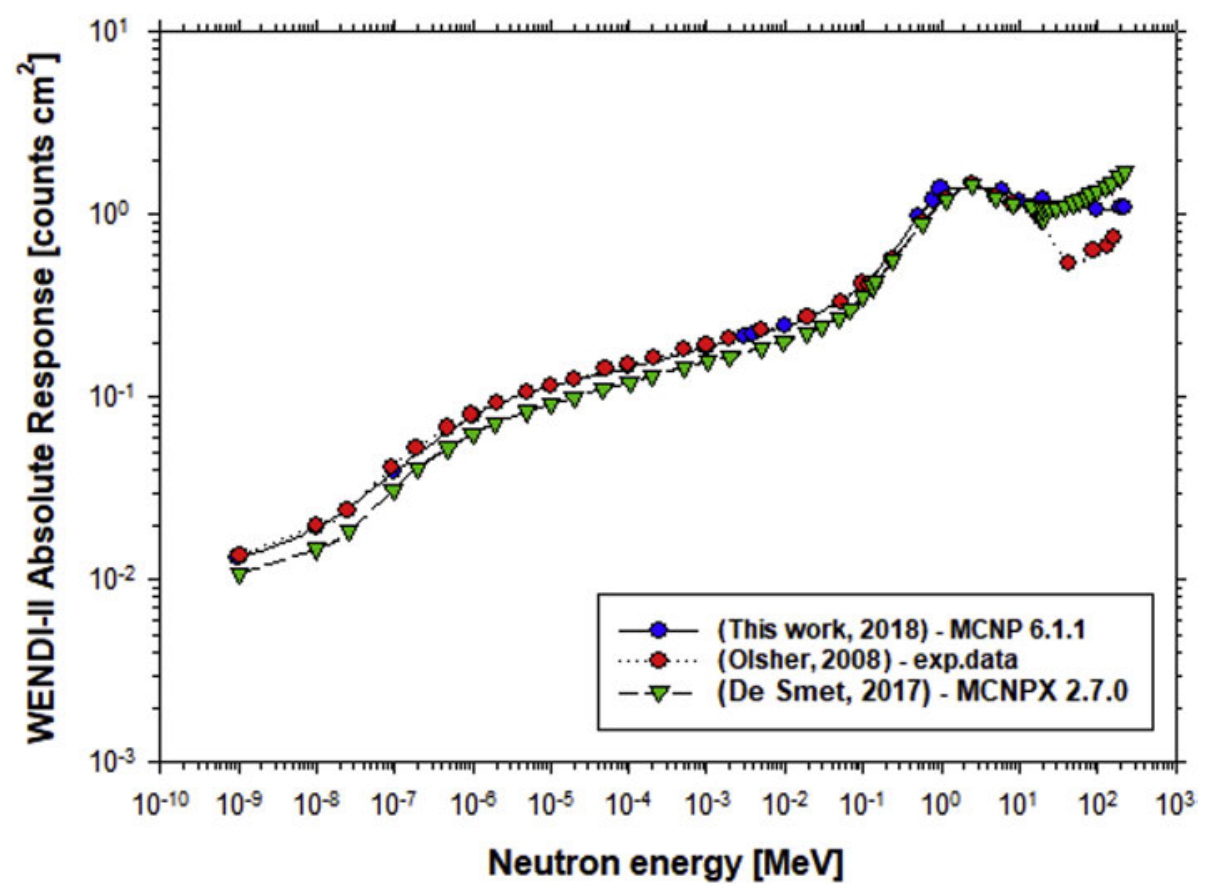

Fig. 6. WENDI-II absolute response (counts $\mathrm{cm}^{2}$ ) compared with former works.

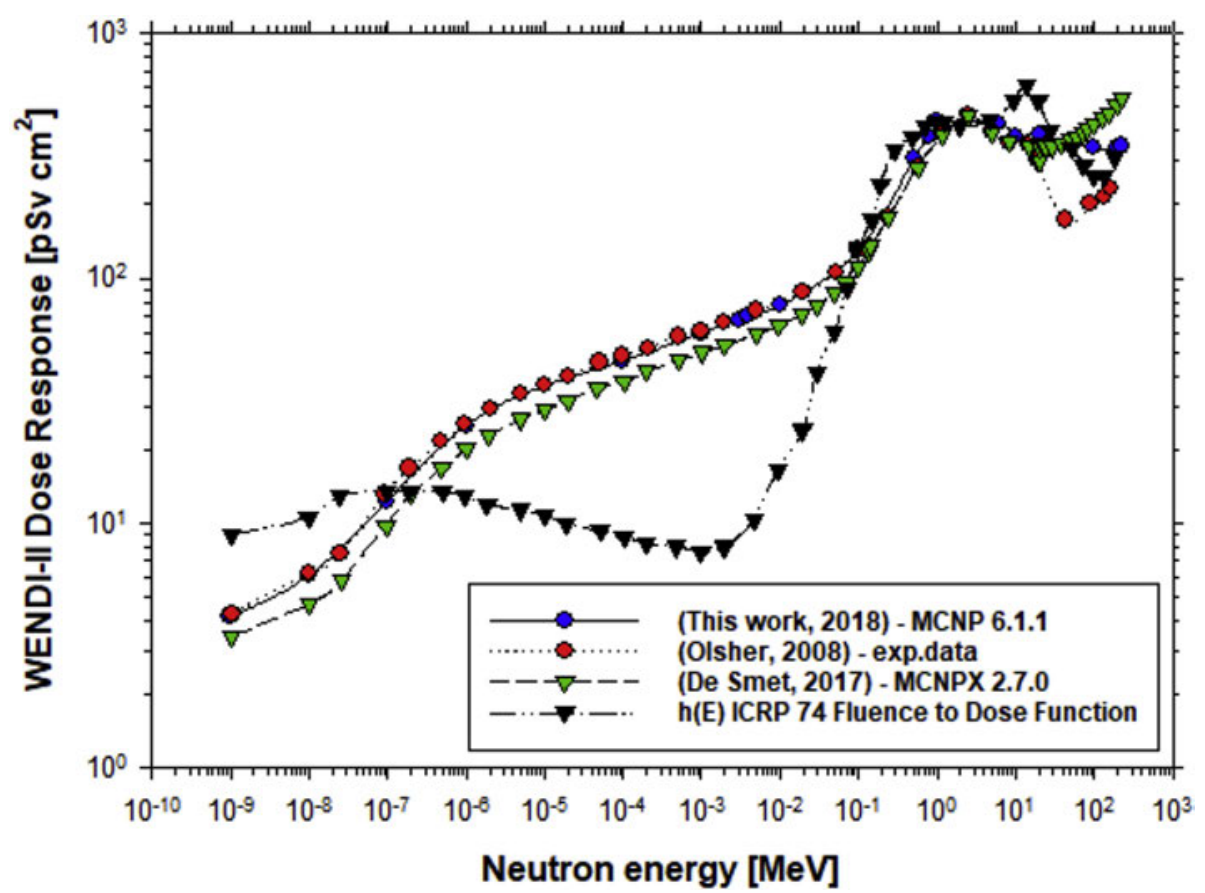

Fig. 7. WENDI-II dose response $\left(\mathrm{pSv} \cdot \mathrm{cm}^{2}\right)$ compared with ICRP 74 function.

Data from LA150 cross section libraries have been used wherever possible (for all isotopes except ${ }^{3} \mathrm{He},{ }^{58} \mathrm{Fe}$ and $\mathrm{Ar}$ ). The available data from the ENDF70prot library was used for the proton cross sections (Conlin et al., 2017). Where experimental cross section data was not available the default physics models of MCNP6 have been used: the Bertini intranuclear cascade, the multistage pre equilibrium exciton and the Dresner evaporation or the Fermi break up model for light nuclei (Pelowitz et al., 2014).

\subsubsection{Channel reactions}

In WENDI II, the main contribution to the count rate is due to the capture reactions of thermalized neutrons in the active gas of the counter, ${ }^{3} \mathrm{He}$, through the reaction ${ }^{3} \mathrm{He}(\mathrm{n}, \mathrm{p})^{3} \mathrm{H}$. The detector efficiency was assumed to be $100 \%$, which means that each neutron triggers a count. There are two additional channels of reaction above $20 \mathrm{MeV}: 1$ ) neutrons produced by photons in tungsten; 2) charged particles pro duced outside the counter tube but tracks through the active volume. According to literauture (Olsher et al., 2000), for neutron energies below $500 \mathrm{MeV}$ these contributions would be less than $3 \%$. Thus, these channels were neglected to the total count rate, because their con sideration in the model would be complex while the accuracy would not be substantially improved. The main contribution to the count rate of LUPIN II is capture of thermalized neutron in the active gas, ${ }^{10} \mathrm{~B}$ in this case, through the reaction ${ }^{10} \mathrm{~B}(\mathrm{n}, \alpha)^{7} \mathrm{Li}$. The detector efficiency of 


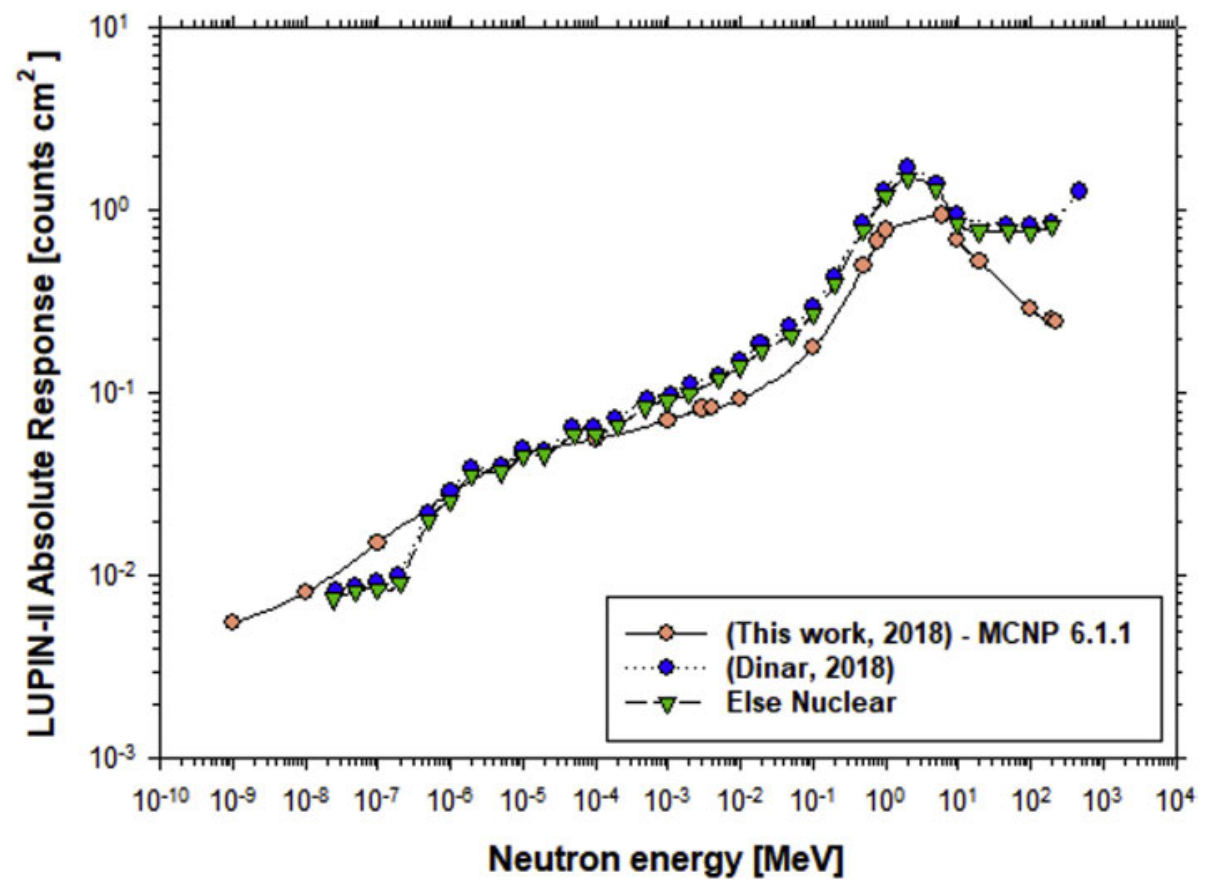

Fig. 8. LUPIN-II absolute response (counts $\mathrm{cm}^{2}$ ) compared with former works.

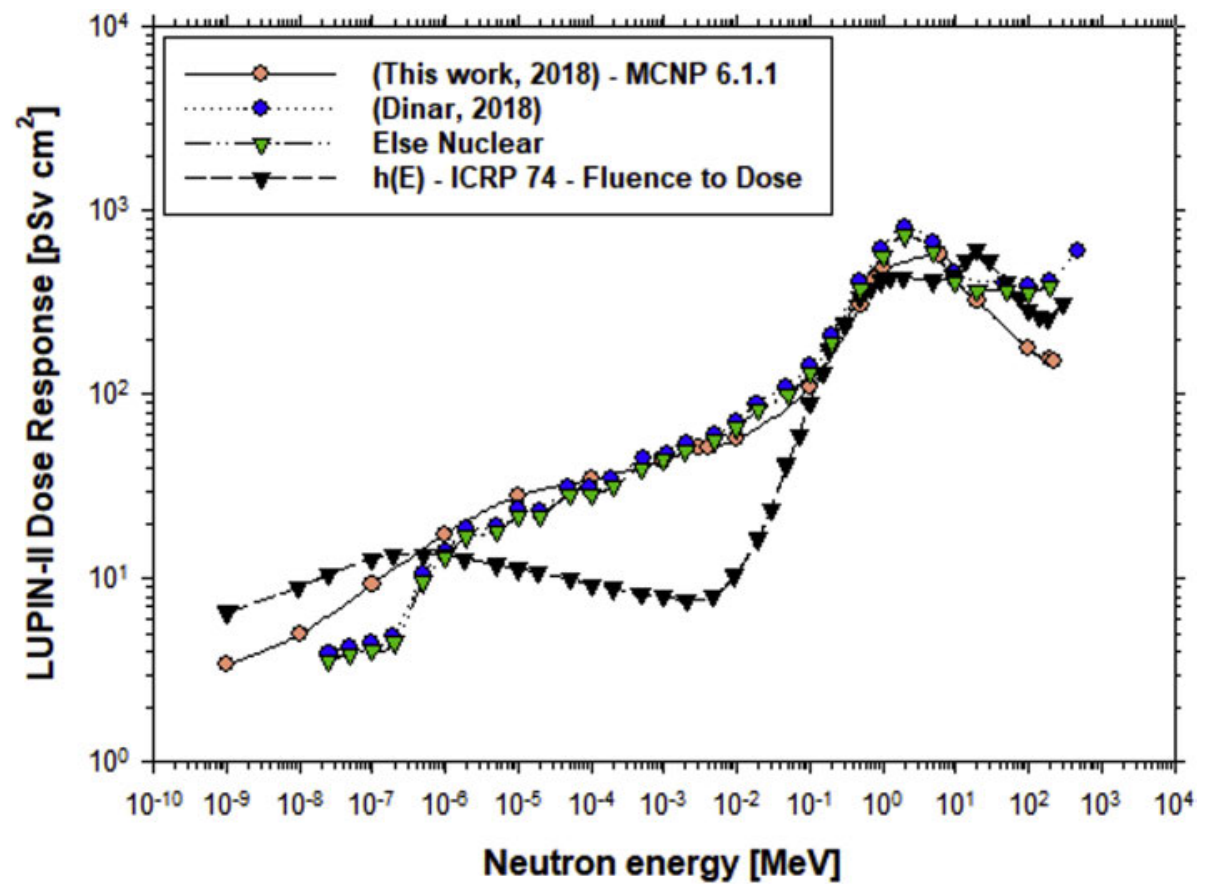

Fig. 9. LUPIN-II dose response $\left(\mathrm{pSv} \cdot \mathrm{cm}^{2}\right)$ compared with ICRP 74 function.

LUPIN II was also assumed to be $100 \%$, considering negligible the re actions carried out by spallation neutrons in lead and the charged particles produced outside the counter tube but tracks through the ac tive volume (Caresana et al., 2014).

\subsubsection{Magnitudes computed in simulations with MCNP6}

2.3.3.1. Absolute response function, in counts per unit neutron fluence (counts $\mathrm{cm}^{2}$ ). The absolute response function was reached computing the total number of counts per unit fluence in the counter tube, and was calculated as the ratio of the average number of reactions $(n, p)$ per source emitted neutron over the counts in air (in a cell equal to the gas volume). The average number of thermal reactions with production of protons in the active volume, (n,p) were computed by folding the average neutron fluence, with the cross section of thermal neutrons in active gas, the atomic density of gas $\left(2.501 \cdot 10^{-5}\right.$ atoms $/ \mathrm{b} \mathrm{cm}$ for ${ }^{3} \mathrm{He}$ of WENDI II, and $7.3 \cdot 10^{-4}$ atoms $/ \mathrm{b}$ cm for ${ }^{10} \mathrm{~B}$ of LUPIN II), and the active volume of the counter $\left(23.95 \mathrm{~cm}^{3}\right.$ in WENDI II and $73.63 \mathrm{~cm}^{3}$ in LUPIN II).

The theoretical average fluence in air per source emitted neutron in WENDI II is $0.00142 \mathrm{~cm}^{2}$, in agreement with the emission law, $S=1$ / $\left(\Omega . \mathrm{d}^{2}\right)$, where $\Omega=2 \pi(1 \cos \theta)=0.22 \mathrm{sr}$ is the solid angle of the source emission with an angle $\theta=15.20^{\circ}$, and $\mathrm{d}=50 \mathrm{~cm}$ is the distance from the source to the center of active volume. In LUPIN II, the theoretical average fluence per source emitted neutron is $0.00091 \mathrm{~cm}^{-2}$, where 


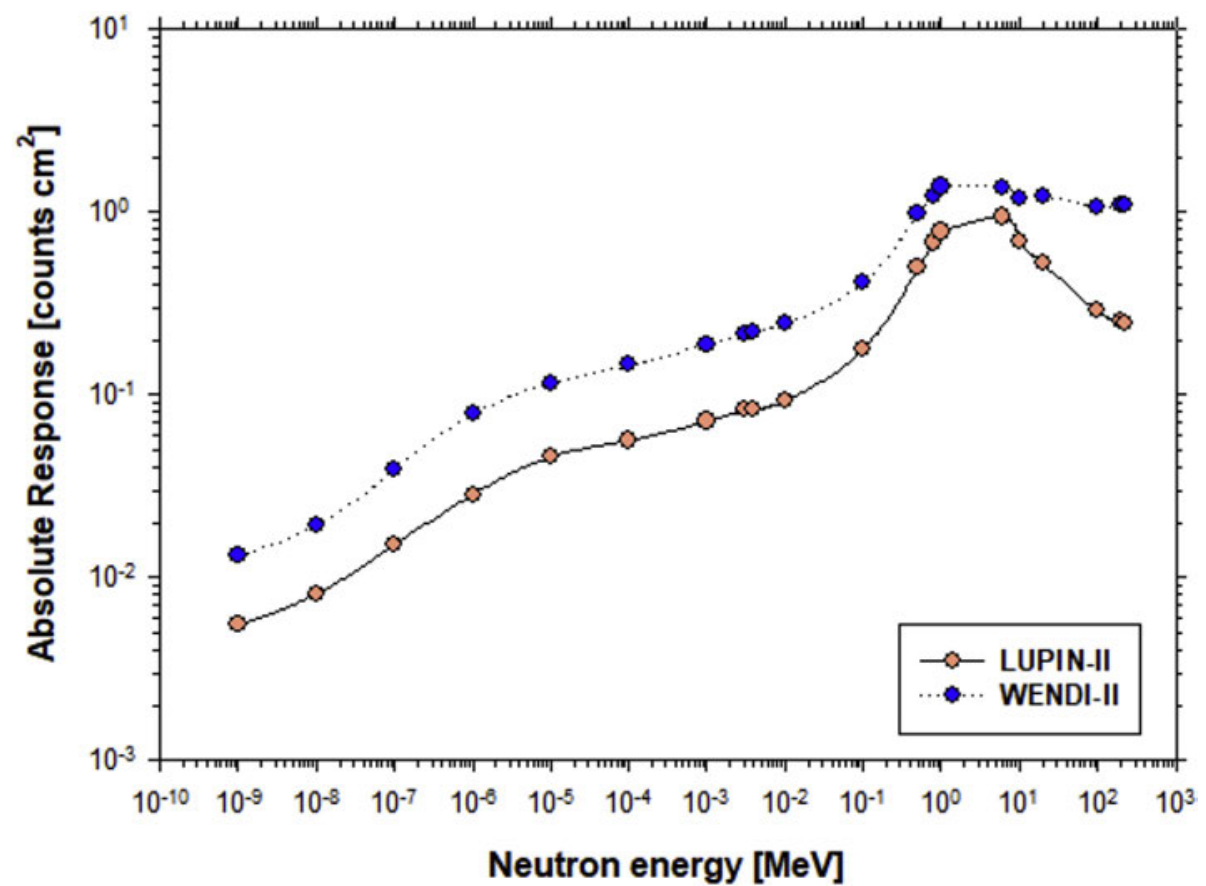

Fig. 10. Benchmark of WENDI-II and LUPIN-II, absolute response (counts $\mathrm{cm}^{2}$ ).

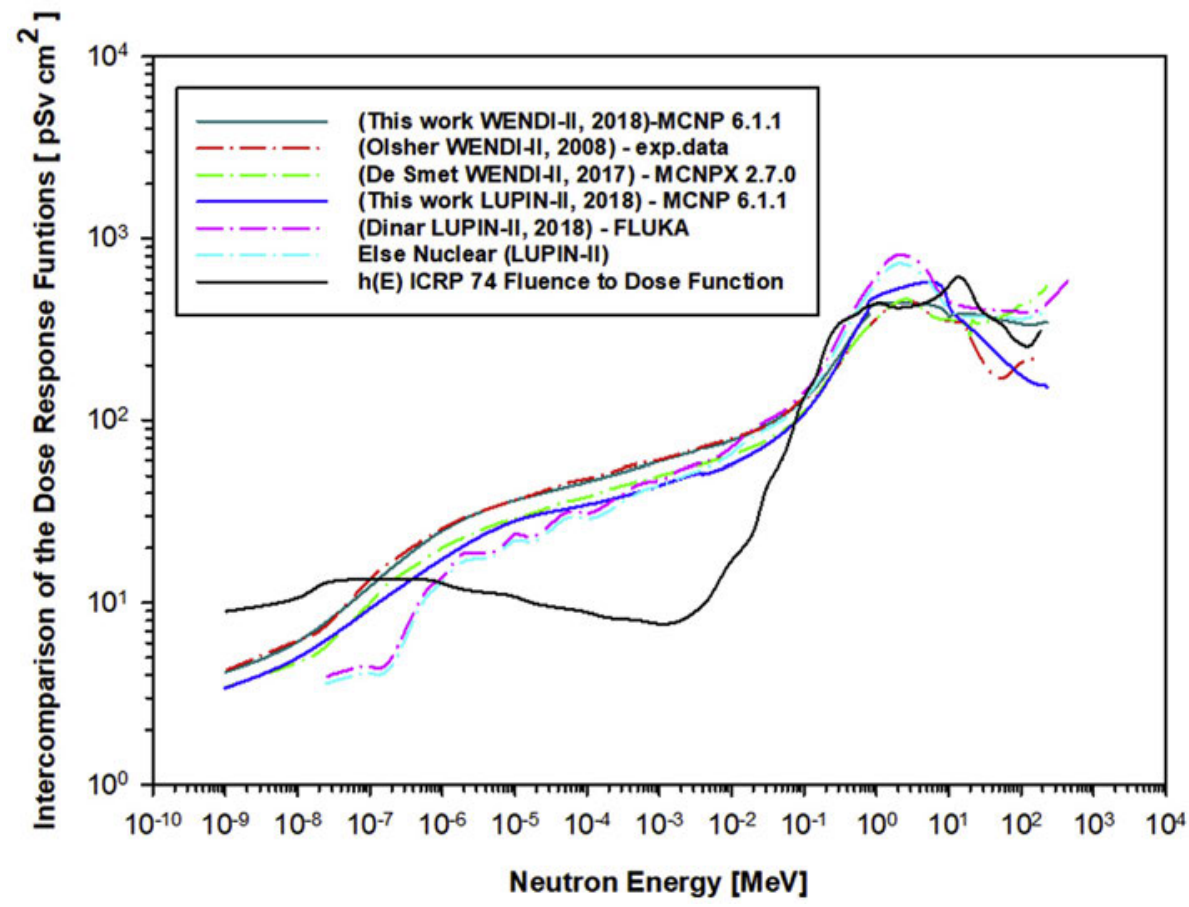

Fig. 11. Benchmark of WENDI-II and LUPIN-II, dose response $\left(\mathrm{pSv} \cdot \mathrm{cm}^{2}\right)$.

$\Omega=0.444 \mathrm{sr}$ is the solid angle of the source emission with an angle $\theta=21.60^{\circ}$, and $\mathrm{d}$ is also equal to $50 \mathrm{~cm}$.

2.3.3.2. Dose response compared with the ICRP function $\left(p S v \cdot \mathrm{cm}^{2}\right)$. The dose response was obtained as the product of the absolute response function and the calibration factor of detector, C, to comparing with the ICRP 74 fluence to dose conversion function (Table A.422) (ICRP, 1996). This calibration factor converts the counts $\mathrm{cm}^{2}$ into a dose response function in $\mathrm{pSv} \cdot \mathrm{cm}^{2}$. Following Olsher (2000), for WENDI II, $\mathrm{C}$, would be the product of sensibility, $\mathrm{S}$, and the wall effect, $\mathrm{W}_{\mathrm{ef}}$. The sensibility for an LND 252180 tube is 0.84 (counts $/ \mathrm{s}) /(\mu \mathrm{Sv} / \mathrm{h}$ ),
$\mathrm{S}=330.7 \mathrm{pSv} /$ count, in agreement with the manufacturer. The wall effect was determined experimentally with a bare ${ }^{252} \mathrm{Cf}$ source for a GL 2500802 NS counter tube by Olsher (2000), $W_{\text {ef }}=0.743$. Then, the calibration factor would be $\mathrm{C}=\mathrm{S} \cdot \mathrm{W}_{\mathrm{ef}}=330.7 \mathrm{pSv} /$ count $0,743=245.7 \mathrm{pSv} /$ count. This factor has been updated in later publications and for the present work, $\mathrm{C}=0.317 \mathrm{nSv} /$ count, calibrated with a bare ${ }^{252} \mathrm{Cf}$ source (Olsher and McLean, 2008). For LUPIN II the calibration factor with an AmBe source, taken for this work has been $\mathrm{C}=0,463 \mathrm{nSv} /$ count (Else Nuclear, 2018).

2.3.3.3. Relative dose response normalized to ICRP fluence to dose 


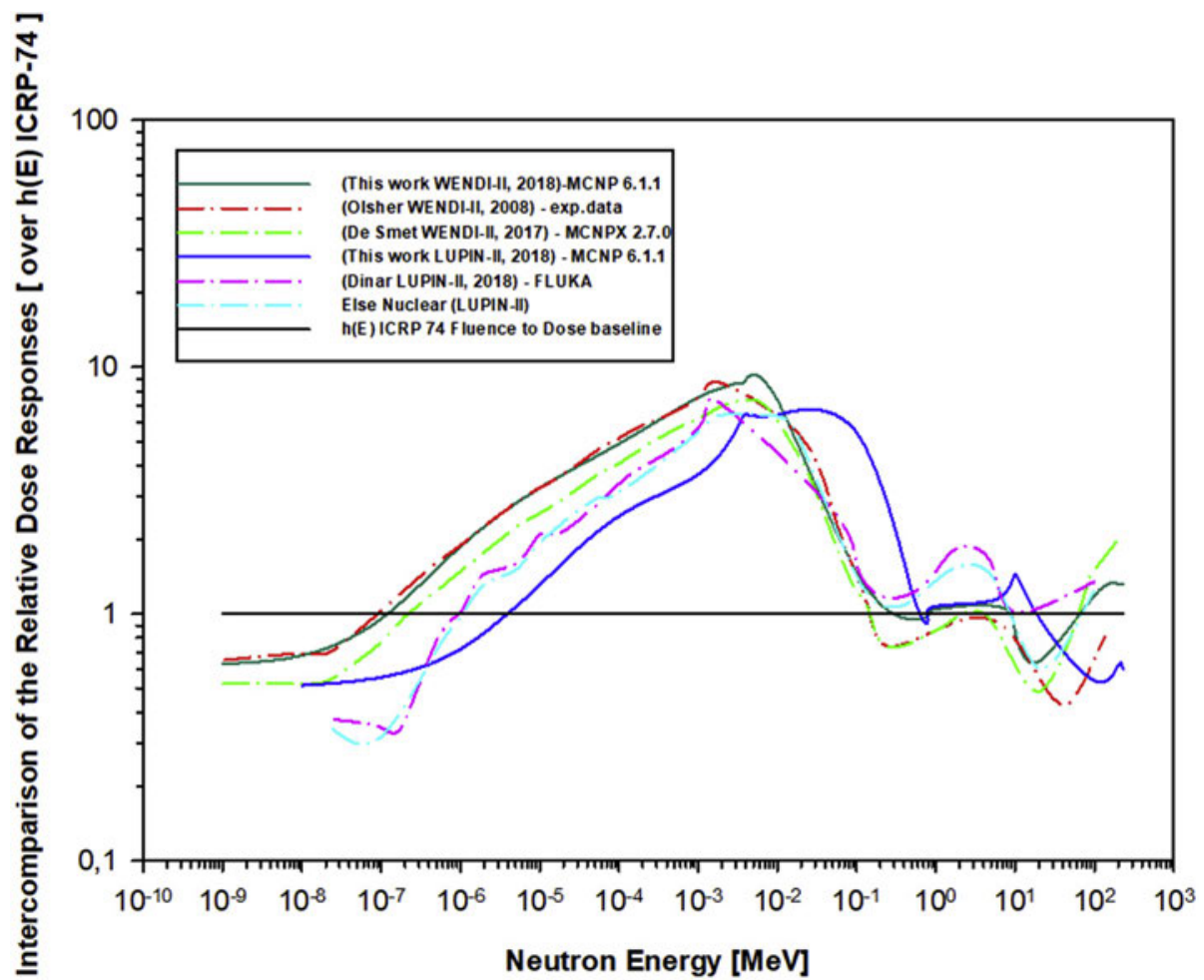

Fig. 12. Benchmark of WENDI-II and LUPIN-II over ICRP 74 function.

Table 3

MCNP6 response results in continuous neutron fields (counts/s).

\begin{tabular}{|c|c|c|c|c|c|c|c|}
\hline Position & $\begin{array}{l}\text { Distance from } \\
\text { source }(\mathrm{cm})\end{array}$ & $\begin{array}{l}\text { Count per emitted source } \\
\text { particle WENDI-II }\end{array}$ & $\begin{array}{l}\text { MCNP } 6 \text { Uncertainty } \\
\text { WENDI-II }\end{array}$ & $\begin{array}{l}\text { Count per emitted source } \\
\text { particle LUPIN-II }\end{array}$ & $\begin{array}{l}\text { MCNP } 6 \text { Uncertainty } \\
\text { LUPIN-II }\end{array}$ & $\begin{array}{l}\text { WENDI-II } \\
\text { Response (Counts/ } \\
\text { s) }\end{array}$ & $\begin{array}{l}\text { LUPIN-II Response } \\
\text { (Counts/s) }\end{array}$ \\
\hline 1 & 50 & $4.807 \times 10^{5}$ & $6 \%$ & $3.241 \times 10^{5}$ & $3 \%$ & 275,73 & 188.98 \\
\hline 2 & 100 & $1.26 \times 10^{5}$ & $4 \%$ & $8.543 \times 10^{6}$ & $6 \%$ & 69.96 & 49.80 \\
\hline 3 & 115 & $8.987 \times 10^{6}$ & $4 \%$ & $6.380 \times 10^{6}$ & $7 \%$ & 52.39 & 37.20 \\
\hline 4 & 150 & $5.991 \times 10^{6}$ & $5 \%$ & $4.425 \times 10^{6}$ & $9 \%$ & 34.93 & 25.80 \\
\hline
\end{tabular}

Table 4

MCNP6 results of WENDI-II and LUPIN-II response, and $\dot{H}^{*}(10),(\mu \mathrm{Sv} / \mathrm{h})$.

\begin{tabular}{|c|c|c|c|c|c|}
\hline Position & Distance from source $\mathrm{X}(\mathrm{cm})$ & MCNP6 WENDI-II Response ( $\mu \mathrm{Sv} / \mathrm{h})$ & MCNP6 LUPIN-II Response ( $\mu$ Sv/h) & MCNP6 $\dot{\mathbf{H}}^{*}(10)(\mu \mathrm{Sv} / \mathrm{h})$ & $\operatorname{MCNP} 4 \mathrm{C} \dot{\mathbf{H}}^{*}(10)(\mu \mathrm{Sv} / \mathrm{h})$ \\
\hline 1 & 50 & $314 \pm 18$ & $315 \pm 10$ & $318 \pm 13$ & $322 \pm 16$ \\
\hline 2 & 100 & $80 \pm 4$ & $83 \pm 5$ & $84 \pm 3$ & $85 \pm 4$ \\
\hline 3 & 115 & $60 \pm 3$ & $62 \pm 4$ & $64 \pm 2$ & $65 \pm 3$ \\
\hline 4 & 150 & $40 \pm 2$ & $43 \pm 4$ & $44 \pm 1$ & $40 \pm 2$ \\
\hline
\end{tabular}

conversion function. As a final summary of results in monoenergetic fields, the dose response function was compared with the ICRP 74 fluence to dose function (ICRP, 1996) for both REM meters, through the normalization of dose response over the ICRP coefficient for each energy.

\subsection{Simulation response of REM meters in continuous neutron fields}

Response of REM meters in real continuous neutron fields have also been carried as a first step of characterizing the detector in CPTC, considering the AmBe/241 source of the Neutronics Hall $(\mathrm{NH})$ of Neutron Measurements Laboratory of the Energy Engineering Department of Universidad Politecnica de Madrid (LMN UPM). The NH was modeled in MCNP6 as shown in Fig. 5, including the bench, the REM meter and the AmBe/241 source, with its real dimensions and composition (Vega Carrillo et al., 2012). The intensity considered for the source was (5.83 \pm 0.14$) \cdot 10^{6} \mathrm{n} / \mathrm{s}$ (Vega Carrillo et al., 2009).

The ambient dose equivalent $\mathrm{H}^{*}(10)$ rate has been calculated in four positions, at distances $X=50,100,115$ and $150 \mathrm{~cm}$ from de center of source, respectively, similar to former work (Vega Carrillo et al., 2003). Likewise, the response of WENDI II and LUPIN II placed in the same four positions was obtained by MCNP6, with the real neutron source. The responses in $\mu \mathrm{Sv} / \mathrm{h}$ have been estimated by multiplying the average number of reactions (n,p), per source emitted neutron, $5.83 \times 10^{6} \mathrm{n} / \mathrm{s}$, assuming a calibration factor of $\mathrm{C}=0.317 \mathrm{nSv} /$ count for WENDI II and $\mathrm{C}=0,463 \mathrm{nSv} /$ count for LUPIN II.

The simulations in MCNP6 were carried out using F5 tallies, 222 groups neutron spectra, and ENDF/B VII library $\left(\mathrm{E}_{\text {neutrons }}<20 \mathrm{MeV}\right)$, with $10^{8}$ histories (uncertainties less than $5 \%$ ), and including the $S(\alpha, \beta)$ thermal treatment (Pelowitz et al., 2014). The results obtained in the simulations have been compared with experimental measurements using WENDI II, LUPIN II and Berthold LB 6411 instruments, at a 


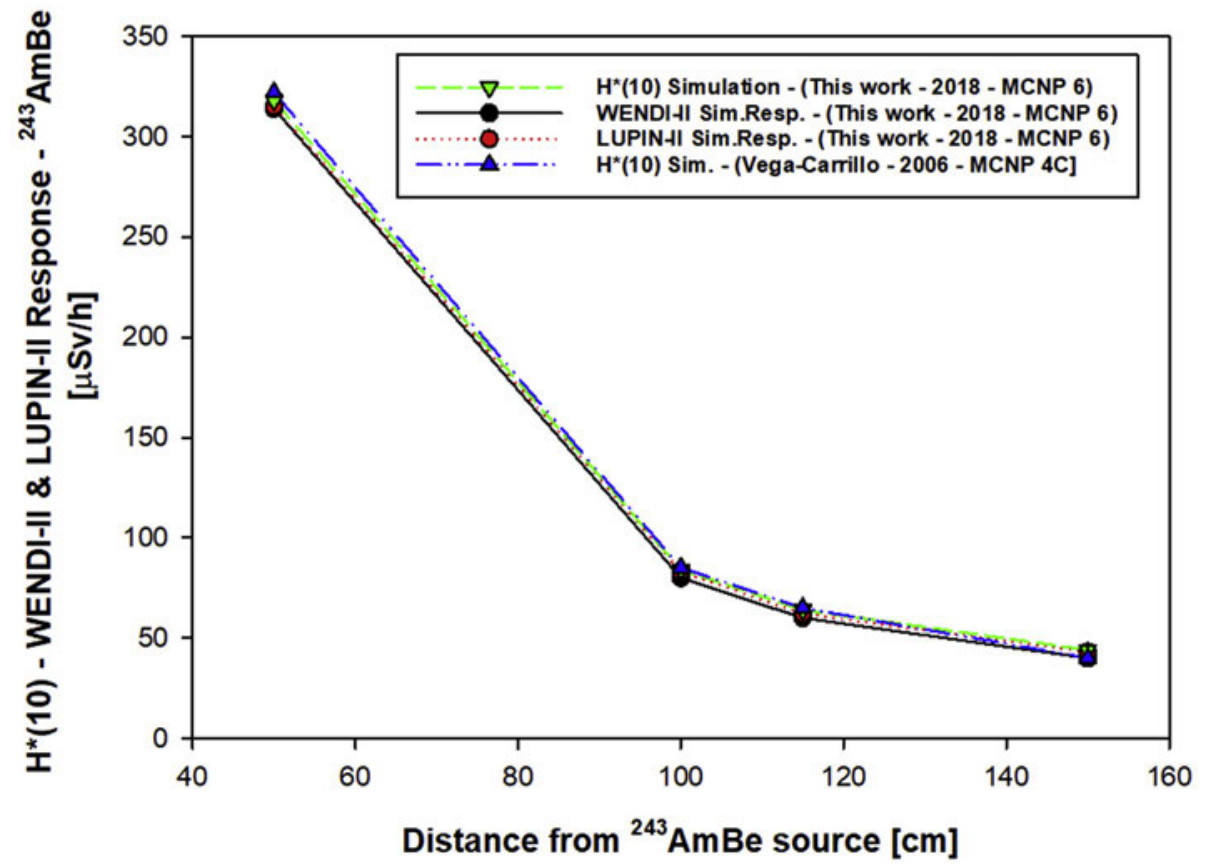

Fig. 13. MCNP6 responses and $\dot{H}^{*}(10)$ dose response at NH of LMN-UPM, $(\mu S v / h)$.

distance $\mathrm{d}=115 \mathrm{~cm}$ from the $\mathrm{AmBe} / 241$ source, according to ISO 8529 (ISO, 1989).

\section{Results}

\subsection{Characterization of WENDI II response in monoenergetic neutron fields}

The absolute response $\mathrm{r}(\mathrm{E})$ in counts $\mathrm{cm}^{2}$ and the dose response compared with the ICRP fluence to dose function $\left(\mathrm{pSv} \cdot \mathrm{cm}^{2}\right)$ of WENDI II, are shown in Figs. 6 and 7, respectively. Both results are bench marked with former works (Olsher and McLean, 2008), obtained with MCNP4B code and experimental measurement (red line), and (De Smet et al., 2017), modeled with MCNPX 2.7.0 (green line). The ICRP function is the black line.

\subsection{Characterization of LUPIN II response in monoenergetic neutron fields}

In the same way, the absolute response $\mathrm{r}(\mathrm{E})$ and the dose response compared with the ICRP function of LUPIN II are shown in Figs. 8 and 9, respectively. Both magnitudes are also benchmarked with previous results (Dinar et al., 2018), modeled with FLUKA (blue line), and (Else Nuclear, 2018), modeled with MCNP (green line). The ICRP function is the black line again.

\subsection{Benchmarking of WENDI II and LUPIN II response in monoenergetic neutron fields}

The benchmarking between WENDI II and LUPIN II was carried out by comparing the absolute response function (counts $\mathrm{cm}^{2}$ ), the dose response, referenced to the ICRP function $\left(\mathrm{pSv} \cdot \mathrm{cm}^{2}\right)$, and the relative dose response, normalized to ICRP fluence to dose conversion function.

The benchmarking of absolute response in monoenergetic neutron fields is shown in Fig. 10. On the other hand, the benchmarking of the dose response compared with the ICRP fluence to dose function is provided in Fig. 11. Finally, Fig. 12 shows the relative dose response over the ICRP function. Former results with both REM meters are in cluded in Figs. 11 and 12.

\subsection{Benchmarking of WENDI II and LUPIN II response in continuous neutron fields}

Results achieved in the characterization of WENDI II and LUPIN II response in continuous neutron fields are collected in Tables 3 and 4. In Table 3 are summarized the REM meters response, in counts per emitted source particle, calculated inside the NH facility of LMN UPM, with MCNP6, at distances $X=50,100,115$ and $150 \mathrm{~cm}$, respectively, from the center of source $\mathrm{AmBe} / 241$.

The dose responses, in $\mu \mathrm{Sv} / \mathrm{h}$, have been obtained by multiplying the responses, in counts/s, by the calibration factor of each REM meter. In Table 4 are collected the calculated response of REM meters and the ambient dose equivalent rate, $\dot{\mathrm{H}}^{*}(10)$, at the same four distances. The uncertainty in the calculation of $\dot{H}^{*}(10)$ was $4 \%$.

The results of dose rate response were compared with former works, at the same facility and with the same source, as shown Fig. 13, where the blue line represents the results carried out with MCNP 4C obtained by Vega Carrillo et al. (2003).

Finally, the results reached with MCNP6 are benchmarked with experimental measurements carried out in the calibration bench of $\mathrm{NH}$ LMN UPM facility, with Berthold LB 6411 detector, WENDI II, and LUPIN II REM meters. Experimental measurements were realized at a distance of $115 \mathrm{~cm}$ from the source, in agreement with ISO 8529. These data are collected in Table 5 and are shown in Fig. 14.

\section{Discussion}

As is shown in Fig. 6 the absolute response of WENDI II has a good agreement with previous works in the literature. Below $1 \mathrm{MeV}$, the values of this work are higher than Olsher a $15 \%$ and a $18 \%$ than De Smet. Between $1 \mathrm{MeV}$ and $100 \mathrm{MeV}$, the values are very close to the former works, Olsher by less than $2 \%$, and the De Smet a $4 \%$. Above $100 \mathrm{MeV}$, the values are greater than Olsher a $20 \%$, and they are similar to De Smet, $5 \%$ higher. The differences in the high energy region could be explained by different nuclear models employed, CEM in the work of Olsher and Bertini in this work and the De Smet. These uncertainties associated with the physic model, and its influence in the absolute re sponse of the detector, could be studied in future works. The data from Olsher were obtained with MCNP4B code and experimental 
measurement.

Regarding the dose response of WENDI II, according to Fig. 7, in thermal energies (until $0.3 \mathrm{eV}$ ), the dose response function under estimates the fluence to $\mathrm{H}^{*}(10)$ conversion function by a factor lower than 2. The same behavior is observed between $150 \mathrm{keV}$ and $0.5 \mathrm{MeV}$ (fast and high energy neutrons). For neutrons with energies between $0.1 \mathrm{MeV}$ and $3 \mathrm{MeV}$, the dose response function overestimates the fluence to $\mathrm{H}^{*}(10)$ conversion function by a factor between 1.4 and 2.2 . The main concern is that for neutrons at intermediate energies, between $3 \mathrm{MeV}$ and $100 \mathrm{MeV}$, exist an underestimation of above 0.5 , because the spallation cross section at these energies is not very large.

According to Fig. 8, the results of the absolute response of LUPIN II are lightly below the references of Dinar (2018) and Else Else Nuclear (2018), due to different physical models in codes for neutron interac tions above $150 \mathrm{MeV}$, FLUKA in the work of Dinar and MCNP5 with Else Nuclear.

However, according to Fig. 9, the results are in good agreement with the fluence to dose function and the dose response of previous works. For low energies, below $10^{-6} \mathrm{MeV}$, the response is under ICRP 74 functions. Between $10^{-6}$ and $2 \mathrm{MeV}$, LUPIN II overestimates the dose, by a factor of up to 7 times. In these areas the coefficients of conversion are very low, hence, underestimation is not usually important in terms of dose, since the neutron fluence to these energies is limited. Finally, for energies over $2 \mathrm{MeV}$, the response is very close to the ICRP curve, slightly above, so there is no a large overestimation but is always conservative, which is very interesting in this area, where the coeffi cients of conversion to dose have really important values.

In the benchmark between WENDI II and LUPIN II, collected in Figs. 10 12, it is observed that WENDI II overestimates the response of the LUPIN II for the whole range of energies considered, therefore, its measurements are more conservative. However, both devices follow roughly the conversion function of ICRP 74.

According to Fig. 13, in the characterization of WENDI II and LUPIN II by measuring $\dot{H}^{*}(10)$ in continuous neutron fields inside the NH of EED UPM, the results reached are in a good agreement with the previous works, both simulations and experimental measures carried out at the same facility. The differences are between a $5 \%$ for the closer position, and a $20 \%$ for the farthest position, always overestimating the former values. Therefore, the measurement is more corrected with a spectrum closer to the original spectrum of emission from the source. The results with different MCNP6 versions are very similar.

In accordance with the last experimental measurements, carried out in June 2018 for WENDI II and Berthold, and May 2019 for LUPIN II, the results, summarized in Table 5 and Fig. 14, show that WENDI II measurements are closer than LUPIN II to the experimental data ob tained with Berthold. These measurements have all been made with the same experimental conditions, in agreement with diagram shown in Fig. 5 .

There is a difference of $20 \%$ between the highest value of $67 \pm 4$ $\mu \mathrm{Sv} / \mathrm{h}$, obtained experimentally with LUPIN II, and the lowest value of $56 \pm 1 \mu \mathrm{Sv} / \mathrm{h}$, reached also experimentally, but in this case with WENDI II. Nevertheless, the experimental value with LUPIN II is closer to the value of $64 \pm 2 \mu \mathrm{Sv}$ /obtained with MCNP6. These differences could be due to the different behavior of the spallation materials used in each REM meter, lead for LUPIN II and tungsten for WENDI II, since the energies of the AmBe/241 source are low. It could also influence the different state of the materials of spallation, and the tungsten in WENDI II is in powder form, while the lead in LUPIN II is a solid plate.

\section{Conclusions}

The characterization, evaluation and benchmarking of two com mercial extended range REM meters, WENDI II and LUPIN II, for its application in shielding verifications and radiation area monitoring in Compact Proton Therapy Centres (CPTC) has been carried out by Monte 


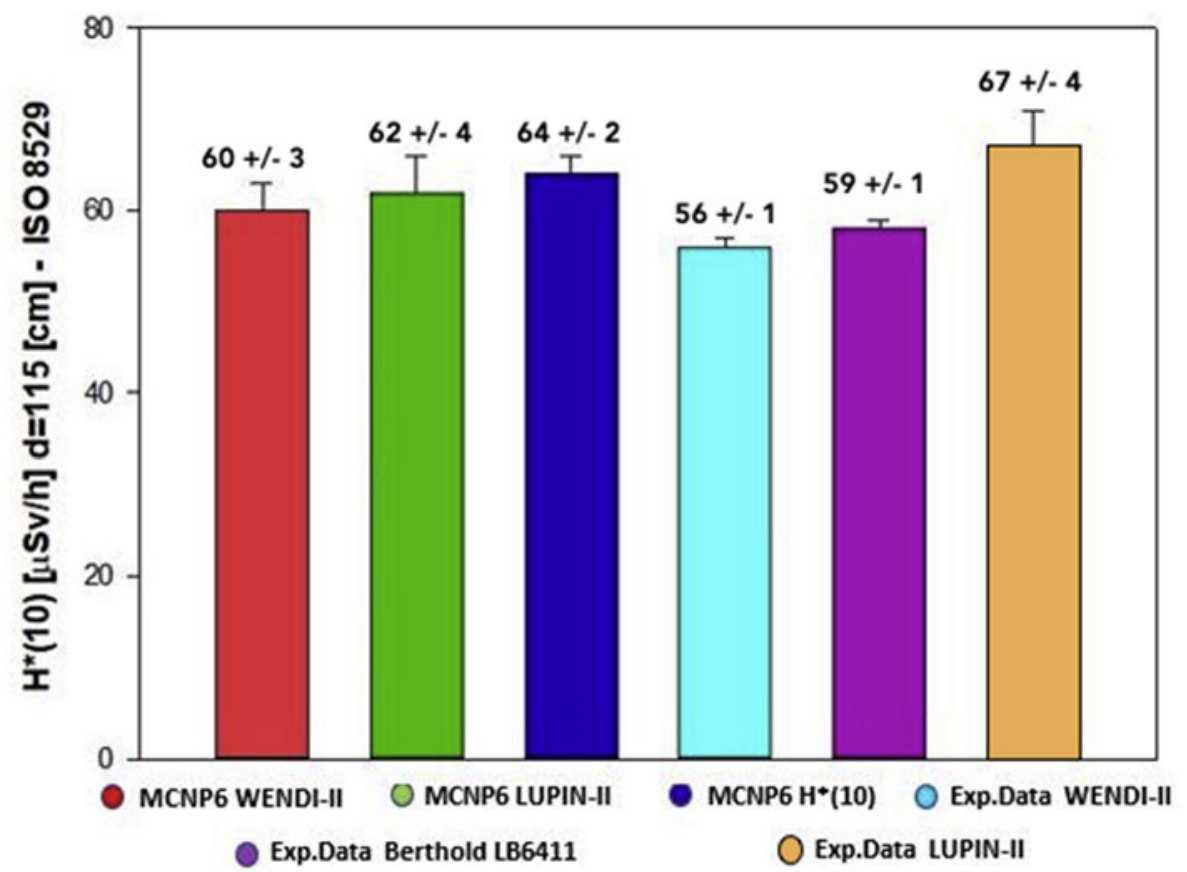

Fig. 14. Benchmark of MCNP6 simulations and experimental measurements at NH LMN-UPM facility $(\mu \mathrm{Sv} / \mathrm{h}$ ), at a distance $\mathrm{d}=115 \mathrm{~cm}$ from source (ISO 8529 ).

Carlo techniques by using the MCNP6 version 6.1.1 code, and experi mental measurements, finding a high agreement with the former works consulted and technical specifications from the manufacturers.

The characterizations were carried out by calculating the absolute response function of the detectors (counts $\mathrm{cm}^{2}$ ), and the dose response, referenced to the ICRP function $\left(\mathrm{pSv} \cdot \mathrm{cm}^{2}\right)$, in monoenergetic neutron fields. Results were compared with similar works existing in literature, obtained with previous versions of the MCNP code. The higher over estimation is at $5 \mathrm{keV}$, a factor of 9 for WENDI II, and at $2 \mathrm{keV}$, a factor 7.5 for LUPIN II.

The benchmarking between REM meters was carried out by com paring the absolute response function, the dose response, referenced to the ICRP function, and finally the relative dose response over the flu ence to dose conversion function, $\mathrm{h}(\mathrm{E})$, from thermal energies to $230 \mathrm{MeV}$, with 20 sources of monoenergetic neutrons.

As a first step of characterizing the detector response in real con ditions and continuous neutron fields, MCNP6 simulations of WENDI II and LUPIN II have also been carried out, employing the AmBe/241 source of Neutronic Hall of LMN UPM. The dose response and the $\mathrm{H}^{*}(10)$ dose was compared with a former experimental and simulation work carried out at the same facility and with the same source, finding a high agreement.

Finally, the results reached in the simulations at NH of LMN UPM were compared with experimental measures obtained with Berthold LB 6411 detector, WENDI II, and LUPIN II REM meters. The results achieved are in agreement with the literature and allow concluding that both devices are fit to carry out verification measurements of shielding and characterization of the neutron spectrum in Compact Proton Therapy Centers (CPTC), foreseen in future works inside this project.

\section{Acknowledgments and Funding}

Gonzalo F. Garcia Fernandez has developed this work under the Industrial Doctorate Program, IND2017/AMB 7797, Contributions to Shielding and Dosimetry of Neutrons in CPTC, funded by Madrid Autonomous Region (CM), in accordance with the agreement between the Universidad Politécnica de Madrid and the company Biología y Técnica de la Radiacion, S.L. (Bioterra, S.L.).

Lenin E. Cevallos Robalino, thanks to Secretaria Nacional de
Educación Superior Ciencia y Tecnología of Ecuador (SENESCYT), for the scholarship to carry out postgraduate studies in Madrid, Spain.

Roberto García Baonza thanks the Chair of Nuclear Safety "Federico Goded" between the Consejo de Seguridad Nuclear (CSN) of Spain and Universidad Politécnica de Madrid for the grant received (No. SN1805410112).

\section{References}

Agosteo, S., 2001. Radiation protection at medical accelerators. Radiat. Protect. Dosim. 96, 393-406.

Baumann, M., 2016. Radiation oncology in the era of precision medicine. Nat. Rev. Canc. $16,234-249$.

Birattari, C., Ferrari, A., Nuccetelli, C., Pelliccioni, M., Silari, M., 1990. An extended range neutron rem counter. Nucl. Instrum. Methods A297, 250-257.

Caresana, M., Cassell, C., Ferrarini, M., Hohmann, E., Manessi, G.P., Mayer, S., Silari, M., Varoli, V., 2014. A new version of the LUPIN detector: improvements and latest experimental verification. Rev. Sci. Instrum.(85), 065102.

Conlin, J.L., 2017. Listing of Available ACE Data Tables, LA-UR-17-20709.

De Smet, V., Gerardy, I., Stichelbaut, F., Tolo, S., 2014. MCNPX simulations of the response of the extended-range rem meter WENDI-2. Suppl Nuclear Technoly and Radiation Protection (29), 25-30.

De Smet, V., De Saint-Hubert, M., Dinar, N., Manessi, G.P., Aza, E., Cassell, C., et al., 2017. Secondary neutrons inside a proton therapy facility: MCNPX simulations compared to measurements performed with a Bonner Sphere Spectrometer and neutron $\mathrm{H}^{*}(10)$ monitors. Radiat. Meas. 99, 25-40.

Degiovanni, A., Amaldi, H., 2015. History of hadron therapy accelerators. Phys. Med. 31, 322-332.

Depuydt, T., 2018. Proton therapy technology evolution in the clinic: impact on radiation protection. Ann. ICRP 47 (3-4), 177-186.

Dinar, N., Pozzi, F., Silari, M., Puzo, P., Chiriotti, M., De Saint-Hubert, M., Vanhavere, O., et al., 2018. Instrument intercomparison in the high-energy field at the CERN-EU reference field (CERF) facility and comparison with the 2017 FLUKA simulations. Radiat. Meas. 117, 24-34.

Durante, M., 2017. Charged-particle therapy in cancer: clinical uses and future perspectives. Nat. Rev. Clin. Oncol. 14, 483-495.

Else Nuclear, 2018. LUPIN, Brochure and Technical Information.

Farah, J., et al., 2015. Measurement of stray radiation within a scanning proton therapy facility: EURADOS WG9 intercomparison exercise of active dosimetry systems. Med. Phys. 42 (5), 2572-2584.

Gallego, E., Lorente, A., Vega-Carrillo, H.R., 2004. Characteristics of the neutron fields of the facility at DIN-UPM. Radiat. Protect. Dosim. 110, 73-79.

IAEA, 1998. Radiological Safety Aspects of the Operation of Proton Accelerators. International Atomic Energy Agency, Technical Reports 283, Vienna.

ICRP, 2004. Conversion coefficients for use in radiological protection against external radiation. Ann. ICRP 26, 73-79. 26. ICRP Publication, pp. 3-4.

Ipe, N.E., 2010. PTCOG. Shielding Design and Radiation Safety of Charged Particle Therapy Facilities. PTCOG Report 1. Particle Therapy Cooperative Group. 
ISO, 1989. ISO 8529-1:2001, Preview Reference Neutron Radiations-Part 1: Characteristics and Methods of Production. (Geneva).

Mukherjee, B., 2012. Radiation safety issues relevant to proton therapy and radioisotope production medical cyclotrons. Radiat. Protect. Environ. (35), 126-129 3\&4.

NCRP, 2005. Radiation Protection for Particle Acceleration Facilities. Recommendations of the National Council on Radiation Protection and Measurements, Report 144, Revision. NCRP.

Olsher, R.H., McLean, T.D., 2008. High-energy response of the PRESCILA and WENDI-II neutron rem meters. Radiat. Protect. Dosim. 130, 510-513.

Olsher, R., Hsu, H.-H., Beverding, A., Kleck, J.H., Casson, W.H., Vasilik, D.G., Devine, R.T., 2000. WENDI: an improved neutron rem meter. Health Phys. (79), 170-181. Paganetti, H., 2017. Proton Beam Therapy. IOP Publishing.

Pelowitz, D., Fallgren, A., McMath, G., 2014. MCNP6 ${ }^{\text {TM }}$ User's Manual Code Version 6.1.1
Beta. Report LA-CP-14-0. Los Alamos National Laboratory, USA. PTCOG, 2018. Particle Therapy Facilities Reviewed November 2018. Stichelbaut, F., Closset, M., Jongen, Y., 2014. Secondary neutron doses in a Compact proton therapy system. Radiat. Protect. Dosim. 161 (1-4) 368-37.

Thermo Fisher, 2018. WENDI-2, Brochure and Technical Information.

Vega-Carrillo, H.R., Gallego, E., Lorente, A., 2003. Caracterización del Campo de Neutrones del ${ }^{24} 1 \mathrm{AmBe}$ en una Sala para Calibración. Proccedings of the XIV Congreso Anual SNM/XXI Reunión Anual SMSR. (Guadalajara, Jalisco, México).

Vega-Carrillo, H.R., Gallego, E., Lorente, A., Rubio, I.P., 2009. Campo de neutrones en la sala de medidas neutrónicas de la Universidad Politécnica de Madrid. Reporte UaEn/ RI-NEUT/UPM-03/05260609. (España).

Vega-Carrillo, H.R., Gallego, E., Lorente, A., Rubio, I., Méndez, R., 2012. Neutron features at the UPM Neutronics Hall. Appl. Radiat. Isot. 70, 1603-1607. 